\title{
How Risky are Low-Risk Hedge Funds?*
}

\author{
Olga Kolokolova and Achim Mattes ${ }^{\dagger}$
}

November 17, 2015

\begin{abstract}
This paper investigates the determinants of the average level of risk of hedge funds, which provide high liquidity to their investors and report their returns on a daily basis. We find that larger funds and funds charging higher incentive fees exhibit lower risk, whereas funds charging higher management fees, imposing longer notice periods, and stemming from large fund-families take more risk. There is considerable variation in the risk levels between funds reporting in Euro and USD, with Euro funds being consistently less risky, suggesting that these funds target different types of investors with other preferences.
\end{abstract}

JEL classification: G11; G23

Keywords: Hedge funds; Risk taking; Incentives

${ }^{*}$ Parts of this paper originally circulated within the paper "Recovering Managerial Risk Taking from Daily Hedge Fund Returns: Incentives at Work?". We thank Serge Darolles for his valuable comments and DAAD for partly financing this research.

${ }^{\dagger}$ Corresponding author Olga Kolokolova (olga.kolokolova@manchester.ac.uk) is at the University of Manchester, Alliance Manchester Business School, United Kingdom. Achim Mattes (achim.mattes@unikonstanz.de) is at the University of Konstanz, Department of Economics, Germany. 


\section{Motivation}

Historically, hedge funds were rather opaque investment vehicles, which gave low rights to investors. In particular, long lock-up and redemption notice periods, limiting investors flexibility in redeeming capital, allowed fund managers to use less liquid strategies. Recently, large institutional investors, like pension funds, start to more actively invest into hedge funds. The demand for more transparent and liquid investment vehicles leads to structural shifts in the hedge fund industry. Now, more funds offer favorable redemption terms and higher investor liquidity. Some of them work though managed accounts, allowing daily liquidity. Several platforms, such as, e.g., LYXOR, provide their client opportunities to invest into hedge funds with weekly redemption. Such funds are expected to invest in more liquid assets that match their redemption frequencies.

Much of the recent literature has been devoted to analyzing managerial incentives in hedge funds and their impact on risk taking (Hodder and Jackwerth [2007], Brown et al. [2001], Agarwal et al. [2002], Panageas and Westerfield [2009], Buraschi et al. [2014], Aragon and Nanda [2012], Lan et al. [2013] among others). These papers largely investigate the determinants of changes in fund risk, such as the relative managerial success with respect to peers or fund value relative to the high-water mark. From an investor's point of view, however, knowledge about the changes in risk taking induced by managerial incentives is informative only if an investor is aware of the baseline average risk taking of the fund of interest. This is especially important given the strong persistence of hedge fund risk. Kolokolova and Mattes [2014] find that the intra-month return standard deviation of hedge funds reporting on a daily basis to Bloomberg is strongly serially correlated, which suggests a general risk persistence. Using hedge funds reporting on a monthly basis, Teo [2010] shows that their liquidity risk exposure is persistent, and Ang et al. [2011] document stability of hedge fund leverage.

This paper focuses on the determinants of the average risk within such liquid, and 
presumably, less risky funds. We obtain daily returns of hedge funds from Bloomberg from 2001 to 2011. The number of live hedge funds in the cross-section increases from 52 in October 2001 to almost 500 in April 2011. Figure 1 plots the time series of the total number of functioning funds reporting their returns on a daily basis in our sample.

\section{Figure 1: Total Number of Live Hedge Funds with Daily Reporting Frequency}

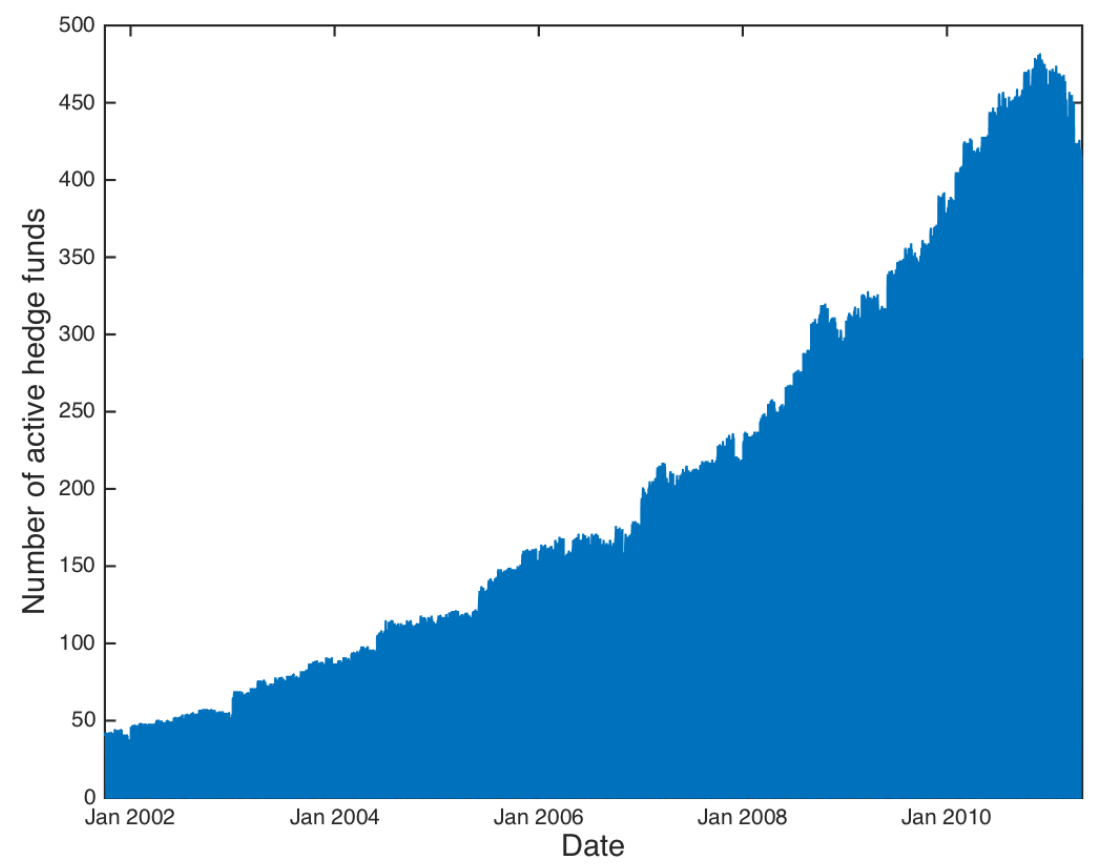

The figure plots the time series of the total number of live hedge funds reporting returns on a daily basis in our sample between October 2001 and April 2011.

We measure the average level of fund risk as the average intra-month return standard deviation. We find a strong positive relation between the level of management fees and the average risk. This finding suggests that hedge funds with higher management fees have stronger incentives to exploit a convex flow performance relationship and, thus, use riskier strategies. Funds charging high incentive fees, on the contrary, tend to exhibit lower risk. We also find some evidence that hedge funds with higher managerial flexibility measured by the length of the notice period prior to redemption exhibit, on average, higher risk. Funds coming from large fund families take on more risk, too. At the same time, larger funds tend to be less risky. 
We document considerable variation in terms of the average risk and its determinants across funds reporting returns in Euro and USD. On average, Euro funds are less risky than USD funds, which is consistent with Joenvaara and Kosowski [2014]. The risk profiles of funds reporting the same investment style are also surprisingly different for Euro and USD funds. Equity Market Neutral funds exhibit the largest differences in terms of the average risk across Euro and USD funds. Fixed Income and Managed Futures funds, on the contrary, are rather similar across currencies. These findings suggest that funds reporting in different currencies target different investors, with different risk attitudes, preferences, and investment goals, which translates into variations in performance and risk of the funds themselves.

The next section introduces the daily hedge fund data and highlights the persistence of risk. Section 3 discusses the methodology and formulates testable hypotheses. Section 4 reports the main empirical results, Section 5 discusses various robustness checks, and Section 6 concludes.

\section{Data}

We use data on 714 hedge funds reporting their returns to Bloomberg from October 1, 2001 through April 29, 2011 in either USD or Euro. This sample was previously used in Kolokolova and Mattes [2014] and it contains live and defunct funds that report on a regular basis. We exclude 17 hedge funds that do not report their investment style. In our sample, there are 22 hedge fund management companies that operate individual hedge funds in two currencies. We manually check those funds and further exclude 6 hedge funds that are likely to be not independent hedge funds, but rather a share class of the same fund reporting returns in a different currency. Table 1 reports descriptive statistics of the average intra-month return standard deviations across eight hedge fund styles. The 
average risk is clearly dispersed across hedge fund styles and currencies. Fixed Income funds have relatively low return standard deviations of $0.23 \%$ and $0.38 \%$ for Euro and USD funds respectively, and Managed Futures funds exhibit one of the highest levels of risk with average return standard deviations of $0.85 \%$ for Euro funds and $0.97 \%$ for USD funds. The largest difference between Euro and USD funds is observed for Equity Market Neutral style with Euro funds having an intra-month returns standard deviation of $0.39 \%$ and USD funds exhibiting a standard deviation of $1.18 \%$.

Table 1: Descriptive Statistics for Average Hedge Fund Risk

\begin{tabular}{l|cccccc}
\hline & \multicolumn{3}{|c}{ EUR } & \multicolumn{3}{c}{ USD } \\
& $\#$ & mean(STD) & std(STD) & $\#$ & mean(STD) & std(STD) \\
\hline Eq Directional & 99 & 0.51 & 0.30 & 69 & 0.75 & 0.54 \\
Eq Mkt Neutral & 90 & 0.39 & 0.36 & 30 & 1.18 & 1.05 \\
Emerg Mkt & 2 & 0.50 & 0.03 & 28 & 0.48 & 0.50 \\
Event Driven & 23 & 0.34 & 0.10 & 11 & 0.49 & 0.30 \\
FI & 45 & 0.23 & 0.22 & 20 & 0.38 & 0.41 \\
Global Macro & 25 & 0.52 & 0.31 & 51 & 0.54 & 0.32 \\
Mgd Futures & 65 & 0.85 & 0.75 & 57 & 0.97 & 0.45 \\
Multi Strat & 42 & 0.32 & 0.17 & 34 & 0.61 & 0.44 \\
\hline
\end{tabular}

The table reports the average intra-month daily return standard deviations for 9 hedge fund styles and two currencies (mean(STD)), as well as its cross-sectional standard deviations $(\operatorname{std}(\mathrm{STD}))$. The underlying daily returns are measured in percent per day.

Figure 2 presents an envelope plot for the time series of the natural logarithm of the intra-month return standard deviations for all hedge funds in our sample, again revealing considerable cross-sectional variation in hedge fund risk, which does not vanish over time.

The cross-sectional differences in risk-taking persist over time. The first order serial correlation of the natural logarithm of intra-month return standard deviation is positive for $91 \%$ of the hedge funds in our sample, with $51 \%$ thereof being statistically significant. This finding reveals short-term persistence in the riskiness of hedge funds. Investors, however, are often subject to notice periods prior to redemption. Our database contains 
Figure 2: Individual Time Series of Hedge Fund Risk

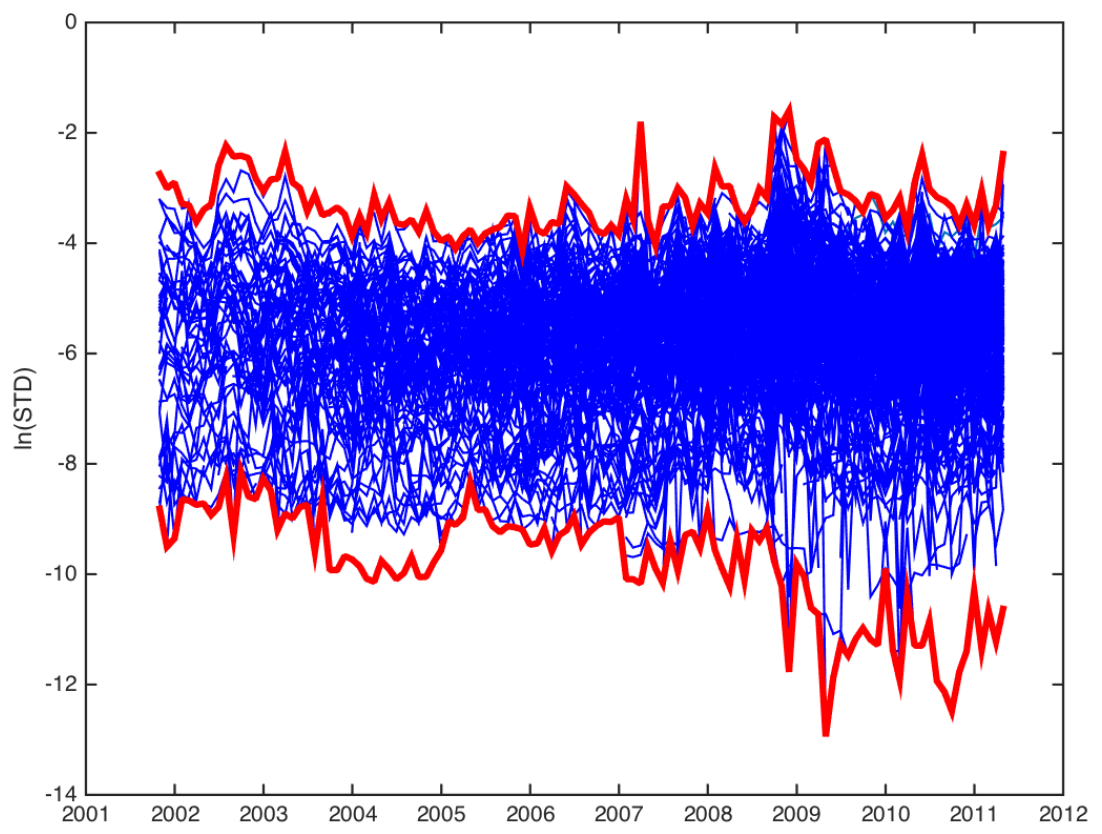

The figure presents an envelop plot from the individual time series of the natural logarithm of the intra-month standard deviations of daily hedge fund returns of all hedge funds in our sample. The sample contains 714 hedge funds that report their returns on a daily basis between October 2001 and April 2011.

relatively liquid funds and the average notice period prior to redemption is only 20 days. But the maximum is 93 days, which means there can be a substantial lag between an investor's decision to exit the fund and the actual time of redemption. To address this issue, for every month, we sort the hedge funds into a high-risk and a low-risk group according to their intra-month return standard deviation being above or below the median, and estimate the probabilities of transition across the groups for different horizons.

Table 2 reports the transition probability matrix. The probability to stay in the same risk category over the following month is much higher than the probability to move to the other category, with the difference being highly statistically significant. The persistence is common for both high- and low-risk funds. We gradually increase the horizon with an increment of one month. The probability to stay in the current risk category is significantly 
higher than the probability to leave it at all horizons until 18 month, where we cannot reject the hypothesis of zero difference between the probabilities anymore for the first time. $^{1}$

Table 2: Transition Probabilities for Hedge Fund Risk Categories

\begin{tabular}{l|lll}
\hline & Low & High & Dead \\
\hline & \multicolumn{3}{|c}{ 1 Month } \\
\hline Low & 84.13 & 13.46 & 2.41 \\
High & 13.56 & 84.16 & 2.29 \\
\hline & \multicolumn{3}{|c}{ 6 Month } \\
\hline Low & 49.54 & 37.00 & 13.46 \\
High & 37.28 & 49.60 & 13.12 \\
\hline & \multicolumn{3}{|c}{ 12 Month } \\
\hline Low & 38.33 & 36.68 & 24.98 \\
High & 36.96 & 38.40 & 24.64 \\
\hline & \multicolumn{3}{|c}{ 18 Month } \\
\hline Low & 32.67 & 32.38 & 34.96 \\
High & 32.62 & 32.72 & 34.66 \\
\hline
\end{tabular}

The table reports the probabilities for hedge funds to move between high-risk and low-risk groups over 1 up to 18 months. The funds are sorted into the risk categories according to the intra-month standard deviation of daily hedge fund returns being above/below the median in a given month. The probabilities are expressed in percent. $* * *, * *$, and $*$ indicate that a probability to stay in the current risk category is significantly different from the probability to leave the category at the $1 \%, 5 \%$, and $10 \%$ significance level, respectively.

Hedge funds seem to stick to a particular risk level for, on average, a year and a half. The overall persistence of hedge fund risk levels suggests that while substantial previous research is focused on time-varying drivers of hedge fund risk (e.g. fund value relative to the HWM), general cross-sectional differences, which potentially arise from differential managerial risk appetites and investment strategies, should not be ignored. Such cross-sectional differences may play a dominant role in portfolios containing hedge funds.

\footnotetext{
${ }^{1}$ We repeat the analysis for high-risk and low-risk funds separately, for USD and Euro funds separately, as well as for changes in risk from December (one year) to January (the next year) only. The results remain virtually unchanged.
} 


\section{Methodology and Hypotheses Development}

To analyze the determinants of hedge fund risk, we run cross-sectional regressions with the dependent variable measuring the average level of risk for each hedge fund. It is calculated as the natural logarithm of the average intra-month standard deviation of daily hedge fund returns $\left(\ln \left(\overline{S T D}_{i}\right)\right){ }^{2}$ The set of explanatory variables includes hedge fund characteristics potentially influencing the overall fund risk $\left(X_{i}\right)$ and several control variables $\left(Z_{i}\right)$.

$$
\ln \left(\overline{S T D}_{i}\right)=\alpha+X_{i}^{\prime} \beta+Z_{i}^{\prime} \gamma+\epsilon_{i}
$$

As the dependent variable (the average intra-month return standard deviation) is an estimate of the expected return volatility, we compute bootstrapped standard errors for our statistical inference on the estimated regression coefficients.

Below we review each of the potential determinants of hedge fund risk, and formulate testable hypotheses.

\subsection{Managerial Incentives and Flexibility}

Managerial incentives and flexibility can affect the average level of risk-taking by hedge funds. The general consensus in the literature is that the existence of a HWM provision, the levels of incentive and management fees, as well as the length of lock-up and notice periods have an impact on the managerial risk taking. The empirical as well as the theoretical evidence on the directions of the relations between these factors and the level of risk is, however, mixed.

\footnotetext{
${ }^{2}$ In this paper, we deliberately focus on the average level of risk. An alternative approach would be to incorporate time-series dynamics too using a panel model. See Darolles [2014] for an example of simple panel regression analysis of hedge fund returns.
} 
Hedge fund managers (especially those with a short investment horizon) increase the risk of their investments, if their compensation contract is convex, that is, if there exists a HWM and managers receive an incentive fee, once the fund value is above the HWM by the end of a year Hodder and Jackwerth [2007]. At the same time, as the investment horizon increases, the existence of a HWM can limit the risk taking, as in this case the manager possesses sequential options Panageas and Westerfield [2009]. This observation is in line with the theoretical finding by Ross [2004], that a convex compensation contract does not necessarily lead to increased risk taking. Aragon and Nanda [2012] report supporting empirical evidence that managers of hedge funds with a HWM provision are less likely to shift risk, when their funds underperform. Kolokolova and Mattes [2014] refine this finding and show that a HWM mitigates the risk shifting behavior during the third quarter of a year, but not during the fourth quarter.

Hypothesis A: Hedge funds with a HWM provision take less risk on average.

The managerial option is more valuable, if hedge fund performance fees are high. The performance fees, however, are set by managers at their own discretion. Possibly, only well performing and highly skilled managers with a well established reputation are able to set high performance fees. Cassar and Gerakos [2010] also show that manages of hedge funds with better internal controls charge higher fees. The riskiness of the investment strategies of reputable and well controlled managers is likely to be smaller than that of an average manager. ${ }^{3}$

Hypothesis B: Hedge funds charging higher incentive fees take less risk on average.

To test Hypotheses $A$ and $B$, we consider two regression specifications using information on the existence of a HWM and the incentive fee.

\footnotetext{
${ }^{3}$ At the same time, Kouwenberg and Ziemba [2007] argue, that loss averse managers with higher incentive fees tend to increase the risk of their investments. They find supporting empirical evidence using the Zurich hedge fund universe for both hedge funds and funds of funds.
} 
First, we include in the regression the level of the incentive fee $\left(\operatorname{IncFee}_{i}\right)$ as reported in the database. Second, we use a dummy variable for an incentive fee being above the median $\left(\right.$ IncFeeLarge $\left._{i}\right)$. In both specifications, we use a dummy variable indicating funds with a HWM provision. It allows us to disentangle the pure effect of the existence of a HWM from the impact of high incentive fees.

While the managerial compensation resulting from the existence of a performance fee is convex in fund profitability, the compensation generated by the management fee is linear in hedge fund size. It pays a fixed percentage of the assets under management $(\mathrm{AuM})$ on a pro rata temporis basis. Other things being equal, hedge fund managers would prefer to increase the size of their funds to boost their fee income. There is much evidence in the literature on the convexity of the relationship between fund performance and consecutive fund flows for mutual funds (see Chevalier and Ellison [1997]). Clients tend to invest after superior fund performance more actively, as compared to divestiture in response to poor fund performance. The findings for hedge funds are mixed. Agarwal et al. [2004] find a convex relationship, whereas Goetzmann et al. [2003] document a concave flow-performance relationship. Ding et al. [2009] reconcile this issue, and show that the flow-performance relationship is more complex, changing from convex to concave, if a hedge fund imposes share restrictions including longer lock-up and notice periods and has illiquid securities in the portfolio. The higher the management fee, the larger is the share of managerial compensation generated by the part of the compensation contract that is linear in fund size, and, thus, works just like a mutual fund type of contract. If hedge fund managers themselves perceive the flow-performance relationship as convex, increasing fund risk would be a beneficial strategy. The expected gains in case of investment success are larger than the expected losses in case of investment failure. The hedge funds in our sample are rather liquid, with relatively loose share restrictions. Most of the funds in our sample, for example, do not impose any lock-up period. In fact, only seven funds report a non-zero period. According to Ding et al. [2009], one could indeed expect a convex 
flow-performance relationship for such funds. Thus, we expect hedge funds with high management fees to be characterized by a higher level of average fund risk.

\section{Hypothesis C: Hedge funds charging higher management fees take on more risk on average.}

In order to empirically capture this relationship, we, first, include the level of the management fee as reported to the database $\left(M g t F e e_{i}\right)$ in the regression. Second, we use a dummy variable taking a value of one, if the management fee is above the median level $\left(M g t F e e\right.$ Large $\left._{i}\right)$. Third, we recognize that the management fee effect can be more pronounced for large funds. In addition to the management fee dummy, we include the product of the dummy variable indicating a management fee above the median and a dummy indicating an average fund size above the industry median. ${ }^{4}$

Lock-up and redemption periods imposed by hedge funds on their investors assure that hedge fund managers are more flexible in their investment strategies, as the investors cannot demand immediate redemption of their shares. Using monthly data, Agarwal et al. [2009] find that funds with higher managerial flexibility tend to outperform their peers. Higher managerial flexibility also makes it easier to implement illiquid investment strategies and take excessive risks. Thus, we expect funds with greater managerial flexibility to exhibit higher risk levels.

\section{Hypothesis D: Hedge funds with longer notice period prior to redemption take more risk on average.}

We measure managerial flexibility by the length of the notice period prior to redemption expressed in months as reported to the database. We do not consider lock-up periods because only 7 funds report a non-zero period. Again, we include the level $\left(\right.$ Notice $\left._{i}\right)$ and a dummy variable indicating a value above the industry median (NoticeLarge ${ }_{i}$ ) into the regression.

\footnotetext{
${ }^{4}$ There are 61 hedge funds that do not report a management fee and we set the fee to zero here. The results do not change, if we exclude the funds from the analysis.
} 
Hedge funds operating within large fund-families tend to have lower liquidation probability (e.g., Kolokolova [2011] and Aragon and Nanda [2012]). Being to some extent protected by the benefits of belonging to a fund-family, such funds may take higher risks.

Hypothesis E: Hedge funds from larger fund-families take more risk on average.

We capture this effect by a number of funds within a family NFundsFamily which

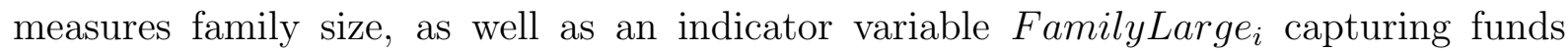
belonging to the $50 \%$ and $25 \%$ of the largest families in turn. Here a family is defined as a group of hedge funds belonging to the same management company.

\subsection{Fund Size and Age}

Hedge fund managers often start their career operating small funds and being rather aggressive in terms of their investment strategy and associated risk taking. However, as funds grow older and larger, they tend to become more conservative. Their outstanding performance tends to deteriorate (e.g. Aggarwal and Jorion [2010]) and the riskiness of their investments can decline. This is largely due to two factors. First, there are diseconomies of scale (Goetzmann et al. [2003]). The scope for truly alternative strategies and arbitrage opportunities is limited. As hedge funds grow larger, the profitable opportunities targeted by the management are getting exploited and exhausted. The new capital has to be allocated to more conventional and liquid investments, which are typically less risky. Second, managers of the established larger and older funds have more to lose in terms of reputation and fee income in the case of fund failure. Thus, the risk taking of larger and older funds is expected to be lower relative to younger and smaller funds. ${ }^{5}$

Hypothesis F: Larger and older hedge funds take less risk on average.

\footnotetext{
${ }^{5}$ There is, however, contrasting evidence for funds of hedge funds by Li and Mehran [2009], who show that younger funds of funds exhibit less total and less systemic risk taking.
} 
Similar to the previously discussed factors, we, first, include the average AuM across the life of a hedge fund converted to millions USD $\left(\ln \left(\overline{A u M_{i}}\right)\right)$ as a measure of size, and the age of a fund expressed in years at the last available return date $\left(\right.$ LifeTime $\left._{i}\right)$ in the regression. Second, we use two indicator variables: a dummy for fund being larger than the median fund $\left(\ln (\overline{A u M}) \operatorname{Large}_{i}\right)$ and a dummy for fund being older that the median fund(LifeTimeLarge Li $_{i}$.

\subsection{Other Determinants of Hedge Fund Risk and Control Vari- ables}

The hedge funds in our sample report their returns in different currencies with $56 \%$ (44\%) of all funds reporting in Euro (USD). The average fund return standard deviations are different between Euro and USD funds (see Table 1) and this difference is highly statistically significant. We pool the estimated return standard deviations of Euro and USD funds together, but include a dummy variable for funds reporting in Euro as a control $\left(\right.$ Euro $\left._{i}\right)$. Eighteen hedge funds (2.60\% of our final sample) report their returns in Euro but are not domiciled in Europe. We include the product of the dummy variable for funds reporting in Euro, and another dummy variable indicating non-European domicile, as an additional control (EuroNotEurope E $_{i}$.

As long as hedge fund managers do not switch between completely orthogonal strategies frequently and major alternations in the management teams are rare, the fund risk should be largely determined by the implemented strategy together with the unobserved managerial risk preferences. Hedge funds following different styles, therefore, are likely to exhibit different levels of risk. For example, the average return standard deviation for Emerging Market funds is likely to be higher than for Equity Market Neutral funds, as found by Chan et al. [2007, Table 6.4, p.255]. To capture style variations in the average hedge fund risk, we include seven style dummies in the regression, one for each hedge 
fund style excluding the largest style (Directional Equity), which serves as the reference category.

The hedge fund styles are self reported and style drifts might affect their information content. ${ }^{6}$ We introduce two additional controls to better capture the nature of the hedge fund strategies. The first is the correlation coefficient between the hedge fund returns and the returns on the MSCI World Index over the entire life time of the hedge fund $\left(\right.$ MarketCorr $\left._{i}\right)$. It proxies for the average exposure of a hedge fund to global equity markets. Given the distribution of funds over the different styles in our sample, the vast majority of all funds can be expected to exhibit a positive correlation with the global equity market, and we expect to find a positive coefficient for this control variable. Second, we include the standard deviation of the logarithms of the intra-month return standard deviations over a fund's life time $\left(S T D\left(R I S K_{i}\right)\right)$. It captures the likelihood of style drifts and considerable risk shifting by the hedge fund managers. The cross-sectional correlation coefficient between the standard deviation of log intra-month STD and its average value of -0.13 is significant at the $5 \%$ level. Funds that take higher risks on average, alter their risk levels less and stick more firmly to their risky strategies. Thus, we expect to find a negative coefficient on the standard deviation of risk.

The life times of the hedge funds in our sample span over different time periods. The riskiness of funds operating predominantly during the economic boom in 2005-2006 can substantially differ from the riskiness of funds operating during the sub-prime mortgage crisis of 2007 and the following financial crisis. To control for these differences, the natural logarithm of the average intra-month standard deviation of the daily returns on the MSCI World Index over the life time of a hedge fund $\left(\ln \left(\overline{S T D(\text { Market })_{i}}\right)\right)$ is included in the regression.

Return serial correlation proxies for investment illiquidity and deliberate return smooth-

\footnotetext{
${ }^{6}$ Gibson and Gyger [2007] provide a detailed discussion on hedge fund style classification.
} 
ing by fund managers (Getmansky et al. [2004]). Although return smoothing is less likely to be a problem for more transparent hedge funds reporting on a daily basis, if it does take place, the estimated return standard deviation will be biased downwards relative to its true value. At the same time, technically, if daily returns follow an $\mathrm{AR}(1)$ process, their total variance increases in the level of the autocorrelation keeping the variance of innovations constant. Hence, we include the first order return serial correlation for each fund $\left(\right.$ ReturnCorr $\left._{i}\right)$ as an additional control.

In order to control for possible differences in risk levels between live and defunct funds, we include a dummy variable $\left(\operatorname{Dead}_{i}\right)$, which takes a value of one for hedge funds that stop reporting their performance prior to the final date of the sample.

\section{Empirical Results}

Table 3 reports the estimation results with bootstrapped standard errors for different specifications of Equation 3.1. ${ }^{7}$ With regard to the relationship between the existence of a HWM provision and the average risk taking (Hypothesis A), we cannot find any significant results. The indicator variable for the existence of the HWM is not significant in any of our specifications. There are several reasons that can explain this lack of significance. First, there is still no consensus in the theoretical literature on whether the existence of a HWM should induce higher or lower risk taking. It depends on the type of the utility function of the manager and there might not be any significant effect on average. Second, the relationship between the existence of a HWM and the level of risk is not static and it depends on other time-varying fund characteristics, such as the current position of the fund value relative to the HWM. In this case, on the aggregate level there can be no clear result. Also, the information content of the HMW provision can be covered by the level

\footnotetext{
${ }^{7}$ We include only those funds in the regression analysis for which the complete set of control variables can be computed, including the assets under management. This reduces the sample to 520 funds.
} 
of the performance fee, also included in the regression.

Turning to Hypothesis $B$, the level of the incentive fee does not seem to be a valuable determinant of the average level of fund risk due to its low cross-sectional variation, as the majority of hedge funds charge a $20 \%$ incentive fee. At the same time, the coefficient on the dummy variable indicating a fee above the median level is negative and highly significant. The result supports the intuition of Hypothesis $B$ of a negative relation between the level of the incentive fee and hedge fund risk taking. This relation, however, is driven only by funds charging a fee above the median of $20 \%$, which exhibit lower average risk.

The empirical results strongly support Hypothesis $C$ of a positive relation between the level of the management fee and average fund risk taking. The loadings on both corresponding variables are positive and highly significant $(+0.26$ and +0.28 , respectively). Hedge funds charging higher management fees tend to take higher risks, which is consistent with managerial incentives to exploit the convex flow-performance relationship and increase the fund size.

Managerial discretion measured by the length of the notice period is positively related to fund risk supporting Hypothesis D. On the aggregate level, funds imposing longer notice periods do take higher risks. The loading on the length of the notice period of +0.07 is significant at the $10 \%$ level.

Supporting Hypothesis E, we find that the family size is positively related to risk taking. The loading on the number of funds within the family of +0.01 is significant at the $1 \%$ level. The effect is driven, however, by the largest families only. The indicator variables for funds belonging to the $50 \%$ largest families is not significant in untabulated results. The dummy variable capturing funds from $25 \%$ largest families is highly significant with a loading of +0.24 as reported in Column II of Table 3 .

Fund size is negatively related to the risk taking, consistent with Hypothesis F. The 
Table 3: Cross-Sectional Regressions of Hedge Fund Risk

\begin{tabular}{|c|c|c|c|c|}
\hline & \multicolumn{2}{|c|}{ (I) } & \multicolumn{2}{|c|}{ (II) } \\
\hline Const & $-1.32 *$ & $(-1.92)$ & $-1.95 * * *$ & $(-2.66)$ \\
\hline Euro & $-0.41^{* * *}$ & $(-5.96)$ & $-0.41^{* * *}$ & $(-5.70)$ \\
\hline EuroNotEurope & +0.21 & $(+1.07)$ & +0.21 & $(+1.03)$ \\
\hline EqMktNeutral & -0.14 & $(-1.42)$ & $-0.18 *$ & $(-1.75)$ \\
\hline EmergMkt & -0.26 & $(-1.57)$ & $-0.30 *$ & $(-1.73)$ \\
\hline EventDriven & $-0.42 * * *$ & $(-2.95)$ & $-0.32 * *$ & $(-2.29)$ \\
\hline FixedIncome & $-0.92 * * *$ & $(-7.84)$ & $-0.92 * * *$ & $(-7.76)$ \\
\hline GlobalMacro & -0.17 & $(-1.37)$ & -0.08 & $(-0.65)$ \\
\hline MgdFutures & $+0.44 * * *$ & $(+4.14)$ & $+0.47 * * *$ & $(+4.56)$ \\
\hline MultiStrat & $-0.31 * * *$ & $(-2.77)$ & $-0.28 * * *$ & $(-2.61)$ \\
\hline MarketCorr & $+0.61 * * *$ & $(+5.88)$ & $+0.67 * * *$ & $(+6.06)$ \\
\hline$S T D(R I S K)$ & $-0.43 * * *$ & $(-3.26)$ & $-0.34 * *$ & $(-2.55)$ \\
\hline $\ln (\overline{S T D(\text { Market })})$ & $+0.79 * * *$ & $(+5.76)$ & $+0.70 * * *$ & $(+4.78)$ \\
\hline ReturnCorr & +0.05 & $(+0.19)$ & -0.02 & $(-0.10)$ \\
\hline Dead & -0.11 & $(-1.35)$ & -0.03 & $(-0.40)$ \\
\hline$H W M$ & -0.01 & $(-0.18)$ & +0.02 & $(+0.22)$ \\
\hline IveFee & -0.01 & $(-1.57)$ & & \\
\hline IveFeeLarge & & & $-0.51 * * *$ & $(-4.28)$ \\
\hline MmtFee & $+0.26 * * *$ & $(+6.24)$ & & \\
\hline MmtFeeLarge & & & $+0.28 * * *$ & $(+4.44)$ \\
\hline Redem & $+0.07 *$ & $(+1.86)$ & & \\
\hline RedemLarge & & & +0.11 & $(+1.56)$ \\
\hline NFundFamily & $+0.01 * * *$ & $(+3.65)$ & & \\
\hline FamilyLarge(25\%) & & & $+0.24 * * *$ & $(+2.69)$ \\
\hline $\ln (\overline{A u M})$ & $-0.09 * * *$ & $(-4.48)$ & & \\
\hline $\ln (\overline{A u M})$ Large & & & $-0.11 *$ & $(-1.70)$ \\
\hline LifeTime & +0.02 & $(+1.44)$ & & \\
\hline LifeTimeLarge & & & $+0.14^{*}$ & $(+1.96)$ \\
\hline R-sqr. & 0.46 & & 0.44 & \\
\hline Rbar-sqr. & 0.44 & & 0.42 & \\
\hline Nobs & 520 & & 520 & \\
\hline
\end{tabular}

The table reports estimation results for cross-sectional regressions of the natural logarithm of the average intra-month standard deviation of daily hedge fund returns on a set of hedge fund characteristics and a set of controls. The t-statistics from bootstrapped standard errors are given in parenthesis. ***, **, and * indicate significance at the $1 \%, 5 \%$, and $10 \%$ level, respectively. 
loading on the natural logarithm of the average AuM is -0.09 and significant at the $1 \%$ level. The loading on the corresponding large-fund dummy of -0.11 is significant at the $10 \%$ level indicating that the relation is not driven by large funds only. Including an interaction term between the high management fee dummy and the large fund size dummy does not reveal any significant difference between the partial and the average effects and is dropped from the regression.

There is some evidence on a positive relation between fund life time and fund risk. The dummy variable for life times above the median is positive $(+0.14)$ and significant at the $10 \%$ level. This contradicts the previously developed intuition in Hypothesis F. It seems that the liquid hedge funds reporting returns on a daily basis initially indeed take lower risks. However, as funds grow older, they turn to riskier strategies, as was also found in Li and Mehran [2009] for funds of hedge funds.

Looking at other determinants of the average fund risk, we find considerable variation in fund risk taking with respect to fund style. The Managed Futures funds are the riskiest in our sample with the corresponding loading varying between +0.44 and +0.47 being highly significant and the Fixed Income funds exhibit the lowest overall risk with a highly significant coefficient of -0.92 . The summary statistics in Section 2 already revealed that Euro funds are less risky, which results in a negative and significant loading on the corresponding dummy, but a non-European domicile for Euro funds does not have any significant impact.

The two further factors included to control for hedge fund style (MarketCorr and $S T D(R I S K))$ are both highly statistically significant and show the expected signs. Funds having a higher return correlation with the market tend to be riskier, whereas funds with volatile risk levels take lower risk on average.

A positive and significant coefficient on the mean market risk over the fund life corresponds to hedge fund risk moving in line with market risk. The control for illiquidity and 
return smoothing, as well as the dead fund dummy are not significantly different from zero.

Overall, our analysis suggests that the average level of risk does vary considerably across hedge funds. Larger funds as well as funds charging above median incentive fees tend to be less risky, whereas funds with longer notice periods prior to the redemption and funds belonging to larger families can implement riskier investment strategies. The strongest effect by any means is documented for management fees. Higher management fees induce higher average risk taking by hedge funds' managers. ${ }^{8}$

\section{Robustness}

In this section we perform several robustness checks. First, we exclude some of the control variables which capture hedge fund style. Then, we measure fund risk relative to market risk. Next, we consider different sub-samples and exclude the crisis period. Finally, we repeat the analysis separately for funds reporting in Euro and USD.

\subsection{Empirical Results Excluding Control Variables}

In Section 3.3, we include two control variables into the regression. The correlation between the returns of hedge fund $i$ and the market returns (MarketCorr ${ }_{i}$ ) serves as a data driven proxy for investment style. The standard deviation (over fund's life time) of the natural logarithm of the intra-month return standard deviation $\left(S T D\left(R I S K_{i}\right)\right)$ controls for unstable risk taking potentially resulting from style drifts. Together with the included dummy variables for self reported styles, these two variables capture the part of the overall fund risk, related to fund investment strategy.

\footnotetext{
${ }^{8}$ To check for the robustness of our results, we repeat the cross-sectional analysis using the residuals from a regression of the daily hedge fund returns on the four factors from Carhart [1997], instead of using the returns themselves. The unreported results are consistent with the ones from Table 3.
} 
In order to assess the stability of our results, we systematically drop these control variables from our regression. The corresponding estimation results in Table 4 show, that the key cross-sectional differences in the average levels of hedge fund risk remain highly significant. Hedge fund risk increases in the level of the management fee as well as the length of the notice period, and it decreases with fund size. We conclude that our main findings are robust to variations in the control variables capturing investment style.

Considering the actual controls, we see that the return correlation with the market indeed partially captures style effects. The exclusion of this variable changes the estimated loadings on the style dummies. The most pronounced effect is documented for the Equity Market Neutral funds. In Table 3, the loadings on the style dummy are only significant at the $10 \%$ level in one case. As Equity Market Neutral funds exhibit low correlation with the market, they were unaffected by the large positive loading on MarketCorr in Table 3, in contrast to other styles. Thus, other things being equal, Equity Market Neutral funds exhibit lower levels of risk than their peers having higher return correlation with the market. This effect translates into a negative and highly significant loading on the Equity Market Neutral style dummy in Table 4, when MarketCorr is dropped from the regression. The loading gains significance and its estimated value varies from -0.25 to -0.31 depending on the regression specification. Comparing the results including and excluding $S T D(R I S K)$ (Table 3 vs. Columns (III) and (IV) in Table 4), we do not find evidence of any significant changes. Although the coefficient on the $S T D(R I S K)$ is highly significant in Table 3, the $R^{2}$ drops only slightly when this variable is dropped from the regression.

\subsection{Relative Measure of Hedge Fund Risk}

In this subsection, we define hedge fund risk not in absolute terms, but relative to market risk. We now measure risk as the natural logarithm of the average ratio of the funds' intra-month return standard deviation over the intra-month standard deviation of 


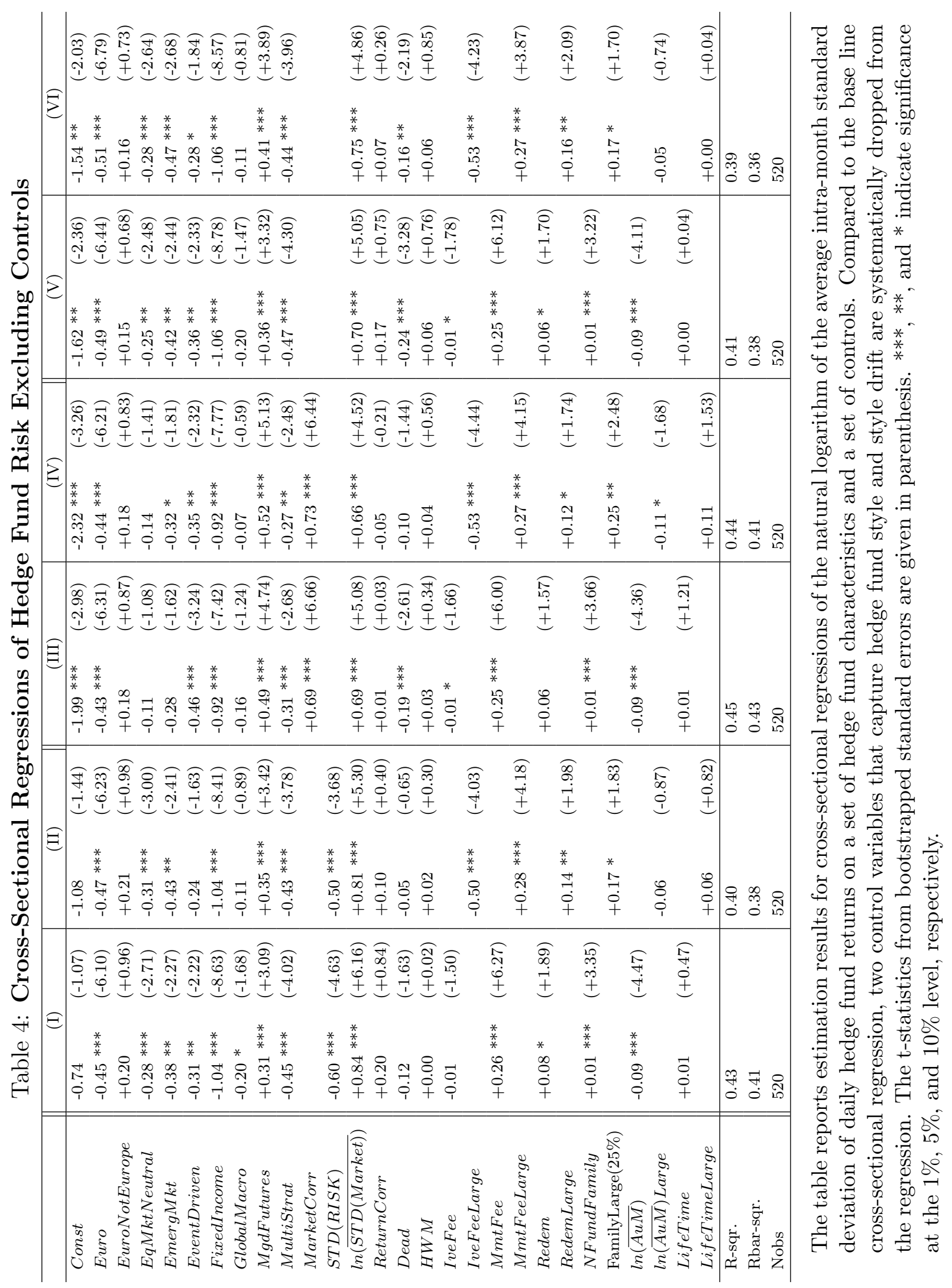


returns on the MSCI-world index over the same month

$$
R I S K M_{i}=\ln \left(\overline{\frac{S T D_{i, t}}{S T D(\text { Market })_{t}}}\right)
$$

The key difference with respect to the results reported in Table 3 is that the market risk variable $\ln \left(\overline{S T D\left(\text { Market }_{i}\right.}\right)$ is no longer significant in this regression. It is not surprising, as market risk is taken out from the dependent variable right away. The remaining results remain stable, and are not tabulated.

\subsection{Excluding Funds without Incentive Fee}

We repeated the cross-sectional analysis excluding 30\% of hedge funds that do not report a positive incentive fee. The results remain very similar to the ones for the complete sample reported in Table 3. The largest change is in the loading on the dummy variable IveFeeLarge, which increases in absolute terms from -0.51 to -0.55 , and remains highly significant.

\subsection{Excluding the Crisis Period}

In this subsection, the cross-sectional analysis is repeated on a pre-crisis subsample, excluding data after July 2007. The results reported in Table 5 are consistent with the ones from Table 3 and seem to be even more pronounced. Most of the significant coefficients increase in absolute values. The main difference is that the interaction dummy variable for funds reporting their performance in Euro while not being domiciled in Europe gains statistical significance and is positively related to hedge fund risk. Fund life time gains marginal significance an is loosely positively related to the average fund risk. Fund-family size, on the contrary, looses significance. 
Table 5: Cross-Sectional Regressions of Hedge Fund Risk Excluding the Crisis

\begin{tabular}{|c|c|c|c|c|}
\hline & \multicolumn{2}{|c|}{ (I) } & \multicolumn{2}{|c|}{ (II) } \\
\hline Const & $-7.05 * * *$ & $(-2.69)$ & $-3.57 *$ & $(-1.69)$ \\
\hline Euro & $-0.70 * * *$ & $(-5.24)$ & $-0.59 * * *$ & $(-4.21)$ \\
\hline EuroNotEurope & $+0.81 * *$ & $(+2.32)$ & $+0.67 * *$ & $(+1.98)$ \\
\hline EqMktNeutral & -0.15 & $(-0.62)$ & -0.32 & $(-1.35)$ \\
\hline EmergMkt & -0.43 & $(-1.40)$ & -0.47 & $(-1.46)$ \\
\hline EventDriven & $-0.98 * * *$ & $(-2.67)$ & $-0.82 * *$ & $(-2.22)$ \\
\hline FixedIncome & $-0.68 * * *$ & $(-2.96)$ & $-0.69 * * *$ & $(-3.22)$ \\
\hline GlobalMacro & -0.01 & $(-0.04)$ & +0.04 & $(+0.14)$ \\
\hline MgdFutures & $+0.51 * *$ & $(+2.48)$ & $+0.57 * * *$ & $(+2.75)$ \\
\hline MultiStrat & -0.29 & $(-1.13)$ & -0.28 & $(-1.08)$ \\
\hline MarketCorr & +0.33 & $(+1.28)$ & +0.31 & $(+1.22)$ \\
\hline$S T D(R I S K)$ & $-0.69 * *$ & $(-2.44)$ & $-0.54 * *$ & $(-2.05)$ \\
\hline $\ln (\overline{S T D(\text { Market })})$ & -0.33 & $(-0.69)$ & +0.35 & $(+0.86)$ \\
\hline ReturnCorr & +0.65 & $(+1.49)$ & +0.53 & $(+1.10)$ \\
\hline Dead & -0.11 & $(-0.74)$ & -0.22 & $(-1.62)$ \\
\hline$H W M$ & +0.21 & $(+1.38)$ & +0.03 & $(+0.25)$ \\
\hline IveFee & $-0.02 * *$ & $(-2.25)$ & & \\
\hline IveFeeLarge & & & $-0.60 * * *$ & $(-2.68)$ \\
\hline MmtFee & $+0.32 * * *$ & $(+4.05)$ & & \\
\hline MmtFeeLarge & & & $+0.53^{* * *}$ & $(+4.26)$ \\
\hline Redem & +0.06 & $(+1.07)$ & & \\
\hline RedemLarge & & & $+0.24 * *$ & $(+2.04)$ \\
\hline NFundFamily & +0.00 & $(+1.00)$ & & \\
\hline FamilyLarge $(25 \%)$ & & & +0.15 & $(+0.85)$ \\
\hline $\ln (\overline{A u M})$ & $-0.07 * *$ & $(-2.11)$ & & \\
\hline $\ln (\overline{A u M})$ Large & & & -0.19 & $(-1.46)$ \\
\hline LifeTime & $+0.04 *$ & $(+1.72)$ & & \\
\hline LifeTimeLarge & & & +0.06 & $(+0.43)$ \\
\hline R-sqr. & 0.52 & & 0.54 & \\
\hline Rbar-sqr. & 0.46 & & 0.48 & \\
\hline Nobs & 187 & & 187 & \\
\hline
\end{tabular}

The table reports estimation results for cross-sectional regressions of the natural logarithm of the average intra-month standard deviation of daily hedge fund returns on a set of hedge fund characteristics and a set of controls. Compared to the base line cross-sectional regression, the financial crisis (starting from June 30th, 2007 onwards) is excluded from the sample period. The t-statistics from bootstrapped standard errors are given in parenthesis. ${ }^{* * *},{ }^{* *}$, and ${ }^{*}$ indicate significance at the $1 \%, 5 \%$, and $10 \%$ level, respectively. 


\subsection{Individual regressions for Euro and USD funds}

In this section we repeat the analysis for the samples of funds reporting in Euro and USD separately. Funds that provide returns in different currencies presumably target investors from different regions, which may have different preferences with respect to the risk-return tradeoff. The estimation results are reported in Table 6. They reveal some differences between the Euro and USD funds in terms of the determinants of their average risk taking.

The negative relation between the incentive fee and fund risk is pronounced only for Euro funds. It is not significant for the USD funds. There are no USD funds in our sample that charge incentive fees above $20 \%$ and also report AuM. Thus, we drop the variable IveFeeLarge when analyzing USD funds. The effect of the management fee is stable and highly significant for both Euro and USD funds. The loadings on the level of the management fees vary from +0.21 for Euro funds to +0.27 for USD funds; and for MgtFeeLarge they vary from +0.23 for Euro funds to +0.35 for USD funds. All loadings are significant at the $1 \%$ level.

Notice period prior to redemption is positively and significantly related to the average fund risk of Euro funds, but the significance weakens, presumably because of the reduced sample. This variable has no significant relation to the risk of USD funds. Fund-family size remains positively related to the riskiness of hedge funds, but the loadings are statistically significant for Euro funds only.

The negative relation between fund size and the average risk seems to be largely driven by Euro hedge funds. The loading on $\ln (A u M)$ of -0.13 is highly significant. For USD funds, the corresponding loadings, albeit still negative, are not statistically significant. At the same time, the loading on LifeTimeLarge for USD funds of +0.25 is significant at the $5 \%$ level (column (4) of Table 6), suggesting that older funds reporting their returns 
in USD exhibit higher average risk taking.

With respect to fund styles, the estimation results indicate that even though hedge funds declare the same style, the nature of the styles may differ depending on whether they are offered to investors requiring Euro or USD returns. For example, the Equity Market Natural USD funds are the riskiest among USD funds, whereas the loading on this strategy is not statistically significant for Euro funds. Multi Strategy funds exhibit the lowest risk within the USD group of funds, but their riskiness is not statistically different from Equity Directional funds (which are used as a base case) for Euro funds. Fixed Income and Managed Futures funds seem to be more consistent across currencies, with the corresponding loadings being similar in their magnitude.

Other control variables, such as return serial correlation, correlation with market returns, and standard deviation of fund risk have consistent impacts on Euro and USD funds.

\subsection{Style Varying Effects of Hedge Fund Characteristics}

In this section, we further test if hedge funds that follow different styles exhibit different sensitivities to analyzed risk-determinants, such as, e.g., management fees. To allow for style variation of factor loadings, we re-estimate the regression from the Equation 3.1 , in which, together with fund characteristics $(X-\mathrm{s})$, we include interaction terms between those characteristics and style dummies. The Equity Direction style is used as a baseline category. The interaction term with this style is dropped from the regression to avoid multicollinearity. We estimate multiple regressions, including interaction terms with each factor in turn. Table 7 reports the estimates of the loadings on the interaction terms together with the baseline category loading. For the sake of brevity, we report only significant estimates. ${ }^{9}$

\footnotetext{
${ }^{9}$ The full set of results is available from the authors upon request.
} 


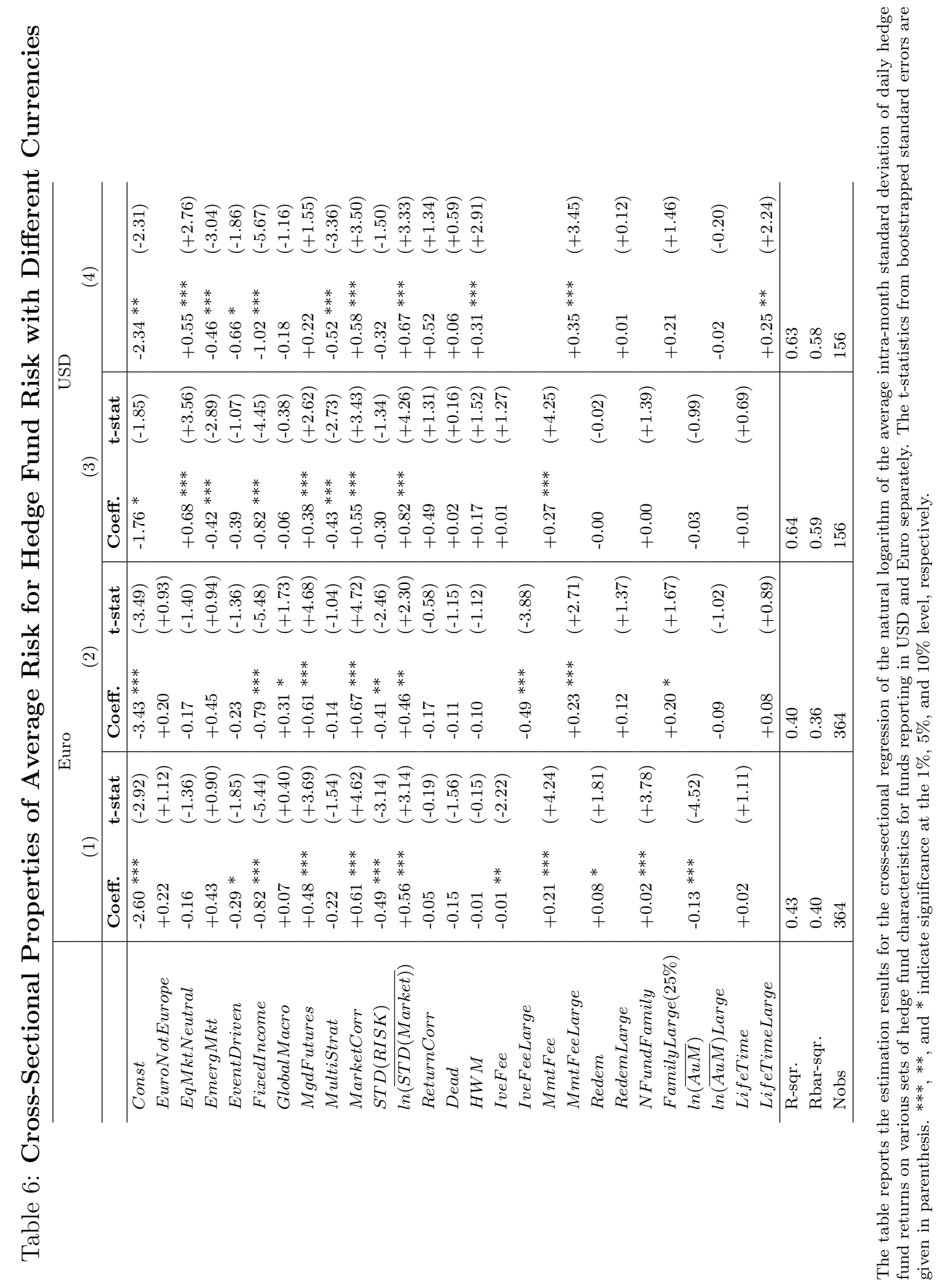


Overall, there is some variation in factor loadings across hedge fund styles, but in most cases the signs are consistent with the results reported in Table 3. The most striking results are associated with the Event Driven funds, though. In the majority of regressions, the differences between the loading for the Event Driven funds and the baseline category are statistically significant and they often suggest opposite relations between factors and fund risk as compared to other funds. This holds for the HWM, incentive fee, fund size, and fund life time. In contrast to most of other styles, Event Driven funds in our sample exhibit higher average risk if they have a HWM provision, charge higher incentive fees, are of bigger size but of younger age. Another instance of sign flipping is found for Fixed Income funds, which also show negative relation between fund life time and risk. ${ }^{10}$

\section{Conclusion}

This paper investigates the cross-sectional differences in hedge fund risk and it complements the vast research analyzing dynamic changes in hedge fund risk taking. We particularly focus on liquid hedge funds that report their returns on a daily basis to Bloomberg. Such funds, which provide favorable redemption terms to investors, are gaining popularity among institutional investors. Their number has risen by a factor of ten over the last decade. Hedge fund risk, measured as the intra-month return standard deviation, exhibits strong cross-sectional variation and is highly persistent. It is, thus, vital for risk management to assess the average risk levels of funds together with the dynamic risk changes in response to managerial incentives, widely discussed in the literature.

We find that besides the hedge fund style, the management and incentive fees, the length of the notice period prior to redemption, fund-family characteristics, and fund size drive the cross-sectional variation in the average level of hedge fund risk. Funds

\footnotetext{
${ }^{10}$ We do not emphasize the results for Emerging Market funds, as there are only 2 such funds in our sample.
} 
Table 7: Style Varying Loadings on Hedge Fund Characteristics

\begin{tabular}{|c|c|c|}
\hline & \multicolumn{2}{|c|}{$H W M$} \\
\hline Average & -0.01 & $(-0.18)$ \\
\hline Baseline style (Eq Directional) & +0.07 & $(+0.47)$ \\
\hline Eq Mkt Neutral & $-0.33^{*}$ & $(-1.67)$ \\
\hline \multirow[t]{2}{*}{ Event Driven } & $+0.67^{* *}$ & $(+1.96)$ \\
\hline & \multicolumn{2}{|c|}{ IveFee } \\
\hline Average & -0.01 & $(-1.57)$ \\
\hline Baseline style (Eq Directional) & $-0.02^{* *}$ & $(-2.04)$ \\
\hline \multirow[t]{2}{*}{ Event Driven } & $+0.04^{* *}$ & $(+2.25)$ \\
\hline & \multicolumn{2}{|c|}{ MgtFee } \\
\hline Average & $+0.26 * * *$ & $(+6.24)$ \\
\hline Baseline style (Eq Directional) & $+0.24^{* * *}$ & $(+2.69)$ \\
\hline \multirow[t]{2}{*}{ Fixed Income } & $+0.30^{*}$ & $(+1.76)$ \\
\hline & \multicolumn{2}{|c|}{$\ln (\overline{A u M})$} \\
\hline Average & $-0.09 * * *$ & $(-4.48)$ \\
\hline Baseline style (Eq Directional) & $-0.11^{* *}$ & $(-2.54)$ \\
\hline Emerg Mkt & $+0.28^{* *}$ & $(+2.01)$ \\
\hline \multirow[t]{2}{*}{ Event Driven } & $+0.16^{*}$ & $(+1.70)$ \\
\hline & \multicolumn{2}{|c|}{$\ln (\overline{A u M})$ Large } \\
\hline Average & $-0.11 *$ & $(-1.70)$ \\
\hline Baseline style (Eq Directional) & $-0.21^{*}$ & $(-1.70)$ \\
\hline \multirow[t]{2}{*}{ Event Driven } & $+0.81^{* *}$ & $(+2.32)$ \\
\hline & \multicolumn{2}{|c|}{ RedemLarge } \\
\hline Average & +0.11 & $(+1.56)$ \\
\hline Baseline style (Eq Directional) & +0.05 & $(+0.38)$ \\
\hline Event Driven & $+0.68^{*}$ & $(+1.87)$ \\
\hline \multirow[t]{2}{*}{ Global Macro } & $+0.53^{* *}$ & $(+2.08)$ \\
\hline & \multicolumn{2}{|c|}{ LifeTime } \\
\hline Average & +0.02 & $(+1.44)$ \\
\hline Baseline style (Eq Directional) & $+0.04^{*}$ & $(+1.86)$ \\
\hline Event Driven & $-0.17^{* * *}$ & $(-2.89)$ \\
\hline Fixed Income & $-0.09^{* *}$ & $(-2.44)$ \\
\hline \multirow[t]{2}{*}{ Global Macro } & $+0.10^{*}$ & $(+1.96)$ \\
\hline & \multicolumn{2}{|c|}{ LifeTimeLarge } \\
\hline Average & $+0.14 *$ & $(+1.96)$ \\
\hline Baseline style (Eq Directional) & +0.19 & $(+1.35)$ \\
\hline Event Driven & $-1.13^{* * *}$ & $(-3.16)$ \\
\hline \multirow[t]{2}{*}{ Global Macro } & $+0.62^{* *}$ & $(+2.43)$ \\
\hline & \multicolumn{2}{|c|}{ NFundFamily } \\
\hline Average & $+0.01 * * *$ & $(+3.65)$ \\
\hline Baseline style (Eq Directional) & $-0.01^{*}$ & $(-1.87)$ \\
\hline Eq Mkt Neutral & $+0.03^{* * *}$ & $(+3.64)$ \\
\hline Event Driven & $+0.09 * * *$ & $(+3.86)$ \\
\hline Fixed Income & $+0.02^{* *}$ & $(+2.12)$ \\
\hline Global Macro & $+0.04^{* * *}$ & $(+3.58)$ \\
\hline Mgd Futures & $+0.02^{* *}$ & $(+2.15)$ \\
\hline Multi Strat & $+0.04^{* *}$ & $(+2.24)$ \\
\hline
\end{tabular}

The table reports the significant estimates of the interaction terms between hedge fund fixed characteristics and style dummies. In each panel, "Average" is the estimated loading on the corresponding fixed factor as reported in Table 3. The "Baseline style" is the estimated loading on the factor for Equity Directional funds, which serves as a reference category. Other reported values are the interaction terms between the factor and style dummies that capture the difference between the loading on the baseline style and the other styles. The t-statistics from bootstrapped standard errors are given in parenthesis. ***,**, and * indicate significance at the $1 \%, 5 \%$, and $10 \%$ level, respectively. 
with higher incentive fees (with the exception of Event Driven funds) take on less risk, which is consistent with them trying to increase the chances for long-term survival. Funds with higher management fees, on the contrary, take more risk, consistent with their managers exploiting the convex flow-performance relationship in order to increase fund size. Investors should therefore be aware that a high management fee does not only, ceteris paribus, decrease their post-fee return, but can also induce increased risk taking. Also, funds with stronger managerial protection, such as longer notice periods prior to redemption and belonging to big fund families, generally take higher risks, whereas larger funds exhibit lower risk levels. 


\section{References}

Vikas Agarwal, Naveen D. Daniel, and Narayan Y. Naik. On determinants of money flow and risk-taking behavior in the hedge fund industry, 2002. Working Paper, Georgia State University.

Vikas Agarwal, Naveen D. Daniel, and Narayan Y. Naik. Flows, performance, and managerial incentives in hedge funds, 2004. Working Paper, Georgia State University.

Vikas Agarwal, Naveen D. Daniel, and Narayan Y. Naik. Role of managerial incentives and discretion in hedge fund performance. Journal of Finance, 64(5):2221-2256, 2009.

Rajesh K. Aggarwal and Philippe Jorion. The performance of emerging hedge funds and managers. Journal of Financial Economics, 96(2):238-256, 2010.

Andrew Ang, Sergiy Gorovyy, and Gregory B. van Inwegen. Hedge fund leverage. Journal of Financial Economics, 102(1):102-126, 2011. ISSN 0304-405X. doi: 10.1016/j.jineco. 2011.02.020.

George O. Aragon and Vikram K. Nanda. Tournament behavior in hedge funds: Highwater marks, fund liquidation, and managerial stake. Review of Financial Studies, 25 (3):937-974, 2012.

Stephen J. Brown, William N. Goetzmann, and James Park. Careers and survival: Competition and risk in the hedge fund and CTA industry. Journal of Finance, 56(5): 1869-1886, 2001.

Andrea Buraschi, Robert Kosowski, and Worrawat Sritrakul. Incentives and endogenous risk taking: A structural view on hedge fund alphas. The Journal of Finance, 69(6): 2819-2870, 2014.

Mark M. Carhart. On persistence in mutual fund performance. The Journal of Finance, 52(1):57-82, 1997. 
Gavin Cassar and Joseph Gerakos. Determinants of hedge fund internal controls and fees. The Accounting Review, 85(6):1887-1919, 2010.

Nicholas Chan, Mila Getmansky, Shane M. Haas, and Andrew W. Lo. Systemic risk and hedge funds. In Mark Carey and Rene M. Stulz, editors, The Risks of Financial Institutions, pages 235-338. University of Chicago Press, Chicago, 2007.

Judith Chevalier and Glenn Ellison. Risk taking by mutual funds as a response to incentives. Journal of Political Economy, 105(6):1167-1200, 1997.

Serge Darolles. Evaluating ucits compliant hedge fund performance. Bankers, Markets and Investors, 133(5):1085-1142, 2014.

Bill Ding, Mila Getmansky, Bing Liang, and Russell R. Wermers. Investor flows and share restrictions in the hedge fund industry, 2009. Working Paper, University of Massachusetts at Amherst.

Mila Getmansky, Andrew W. Lo, and Igor Makarov. An econometric model of serial correlation and illiquidity in hedge fund returns. Journal of Financial Economics, 74 (3):529-610, 2004.

Rajna Gibson and Sbastien Gyger. The style consistency of hedge funds. European Financial Management, 13(2):287-308, 2007.

William N. Goetzmann, Jr. Ingersoll, Jonathan E., and Stephen A. Ross. High-water marks and hedge fund management contracts. Journal of Finance, 58(4):1685-1717, 2003.

James E. Hodder and Jens C. Jackwerth. Incentive contracts and hedge fund management. Journal of Financial and Quantitative Analysis, 42(4):811-826, 2007.

Juha Joenvaara and Robert Kosowski. The effect of regulatory constraints on fund performance: New evidence from ucits hedge funds. Working paper, 2014. 
Olga Kolokolova. Strategic behavior within families of hedge funds. Journal of Banking G Finance, 35(7):1645-1662, 2011.

Olga Kolokolova and Achim Mattes. Recovering managerial risk taking from daily hedge fund returns: Incentives at work? Working Paper, University of Manchester, 2014.

Roy Kouwenberg and William T. Ziemba. Incentives and risk taking in hedge funds. Journal of Banking 6 Finance, 31(11):3291-3310, 2007.

Yingcong Lan, Neng Wang, and Jinqiang Yang. The economics of hedge funds. Journal of Financial Economics, 110(2):300-323, 2013.

Y. Li and J. Mehran. Risk-taking and managerial incentives: Seasoned versus new funds of funds. Journal of Alternative Investments, 11(3):100-108, 2009.

Stavros Panageas and Mark M. Westerfield. High-water marks: High risk appetites? Convex compensation, long horizons, and portfolio choice. The Journal of Finance, 64 (1):1-36, 2009.

Stephen A. Ross. Compensation, incentives, and the duality of risk aversion and riskiness. The Journal of Finance, 59(1):207-225, 2004. ISSN 1540-6261. doi: 10.1111/j.1540-6261.2004.00631.x.

Melvyn Teo. The liquidity risk of liquid hedge funds. Journal of Financial Economics, 100(1):24-44, 2010. 